\title{
Role of Catheter-Directed DX9065a Thrombolysis in the Treatment of Pulmonary Embolism
}

\author{
Yi-Bai Xue* \\ Department of Cardiac Surgery, The First Affiliated Hospital of Nanyang Medical College, Nanyang 473000, China
}

*For correspondence: Email: xueyibai24@gmail.com; Tel/Fax: 0086-377-63328308

Received: 3 March 2015

Revised accepted: 2 July 2015

\begin{abstract}
Purpose: To demonstrate the efficacy of low-dose DX9065a, catheter-directed ultrasound-accelerated thrombolysis (USAT) on the reversal of right ventricle RV dysfunction in patients with pulmonary embolism.

Methods: The analysis of 45 pulmonary embolism PE patients, aged $69 \pm 13.5$ years (range, $28-77$ years) at intermediate- $(n=32)$ or high-risk $(n=13)$ was performed. The patients were treated with USAT and DX9065a (mean dose $35 \pm 8.4 \mathrm{mg}$ over $24 \mathrm{~h}$ ) and received multiplanar contrast-enhanced chest computed tomography (CT) scans at baseline and after USAT at $36 \pm 10 \mathrm{~h}$. CT measurements were then performed.

Results: The results showed a significant decrease in the right to left ventricular dimension ratio $(R V / L V$ ratio) from the baseline value of $1.42 \pm 0.30$ to $1.00 \pm 0.02$ at follow-up $(p<0.001)$. The modified Miller score showed that CT-angiographic pulmonary clot burden was also significantly reduced from $23.2 \pm$ 4.7 to $6.2 \pm 2.5(p<0.001)$. All the patients were discharged alive, and there were no systemic bleeding complications in any of them.

Conclusions: USAT and DX9065a, in low-dose, is a promising strategy for the reversal of right ventricular dilatation and reduction of pulmonary clot in patients with intermediate- and high-risk $P E$.
\end{abstract}

Keywords: Ultrasound accelerated (USAT), DX9065a, Ventricular dimension, Ventricular dilatation, Pulmonary clot, Clot burden, Pulmonary clot

Tropical Journal of Pharmaceutical Research is indexed by Science Citation Index (SciSearch), Scopus, International Pharmaceutical Abstract, Chemical Abstracts, Embase, Index Copernicus, EBSCO, African Index Medicus, JournalSeek, Journal Citation Reports/Science Edition, Directory of Open Access Journals (DOAJ), African Journal Online, Bioline International, Open-J-Gate and Pharmacy Abstracts

\section{INTRODUCTION}

Pulmonary embolism (PE), obstruction in the pulmonary artery is a common state of cardiovascular emergency which can prove to be fatal [1,2]. In the developed countries like United States 600,000 patients are affected out of which 50,000 to 200,000 die every year [3-5]. Among the patients with proximal deep vein thrombosis (DVT), approximately $50 \%$ are detected to have an associated clinically asymptomatic PE present during a heart scan. In approximately $70 \%$ of patients with DVT the clot is located in the lower body if accurate diagnostic method has been used $[6,7]$.

The pulmonary blood obstruction during high-risk PE leads to an early mortality rate of around 50 $\%$ due to failure of right ventricular function [8]. It is reported that thrombolysis is an efficient therapeutic method for the patients with high and intermediate-risk PE and low bleeding risk [9]. Systemic thrombolysis treatment reverses the right ventricular dilatation in a very short span of time compared to the strategies involving use of anticoagulants $[10,11]$. However, the applicability of thrombolysis is hindered by the side effects 
like major haemorrhage and intracranial haemorrhage [12]. Although surgical pulmonary artery thrombectomy is another method for the treatment of thrombolysis but it also carries very high risk of morbidity. Therefore, the search for a more efficient method free from side effects to treat acute PE is being constantly performed.

Fatal damage is often caused by thrombotic events. Therefore, numerous efforts have been made to synthesize antithrombotics such as antiplatelets, anticoagulants, and thromobolytic agents. One such effort was the development of DX-9065a (Figure 1), which acts as an anticoagulant [13]. In the present study, $45 \mathrm{PE}$ patients at intermediate $(n=32)$ or high risk $(n=$ 13) were treated with USAT and DX-9065a.<smiles>CC(=N)N1CCC(Oc2ccc(C(Cc3ccc4ccc(C(=N)N)cc4c3)C(=O)O)cc2)C1</smiles>

Figure 1: Structure of DX-9065a

\section{EXPERIMENTAL}

\section{Patients}

Forty five consecutive patients with high and intermediate-risk PE were treated using catheterdirected USAT (EkoSonic Endovascular System, EKOS Corporation; Bothell; WA) and DX-9065a (Sigma-Aldrich, St. Louis, MO, USA). The patients were selected using the reported criteria [14] which included a) presence of dyspnea, hypoxia, or hemodynamic instability, b) presence of $\mathrm{PE}$ and $\mathrm{c}$ ) right-to-left ventricular dimension ratio $>0.9$. A written consent was obtained from all the patients confirming that they are aware of the nature of the study performed.

\section{Ethical statement}

The experimental process was performed under the supervision of the Ethics Committee of Nanyang Medical College, Nanyang, China, and in accordance with internationally recognized guidelines on human welfare. The study was approved and assigned the reference number SX14- NCT01166997.

\section{Ultrasound studies}

Ekosonic device (The EKOS EkoSonic $\mathbb{R}$ Endovascular system) containing intelligent drug delivery catheter (IDDC), microsonic device
(MSD) with a series of miniature ultrasound transducers positioned along the treatment zone and a Control Unit. The IDDC accommodates the coaxial $0.035 " \mathrm{MSD}$ to deliver uniform radial ultrasound energy (2.2 MHz) to the entire infusion zone with simultaneous DX-9065a infusion. The Control Unit continuously monitors treatment zone temperature and automatically adjusts delivered ultrasound power to optimize thrombolysis. The Ekosonic System is US FDA cleared for the infusion of solutions into the pulmonary arteries.

\section{Treatment regimen}

Heparin (Lovenox, Sanofi-Aventis, Bridgewater, $\mathrm{NJ}) 1 \mathrm{mg} / \mathrm{kg} / 12 \mathrm{~h}$ was given to all the patients received before, during, and after USAT treatment [13]. A $6 \mathrm{Fr}$ introducer sheath (Boston Scientific; Natick, MA) was employed to access both the right and left femoral veins in patients requiring placement of two Ekosonic devices. A $10 \mathrm{Fr}$ dual lumen introducer sheath (Fast Cath Duo; St. Jude Medical; St. Paul, MN) was used for the patients requiring only one venous access site. After placement of introducer sheath a 260 $\mathrm{cm}$ guide wire (Cook, Inc.; Bloomington, IN) and $5 \mathrm{Fr}$ angled pigtail catheter (Boston Scientific; Natick, MA) were penetrated at the desired point. The removal of pigtail catheter was followed by entry of Ekosonic IDDC over the guide wire till catheter was within the embolus. Thereafter, MSD containing the ultrasound transducers was exchanged with guide wire and the saline with heparin was infused through IDDC followed by delivery of ultrasound energy. Patients treated early in the series received DX-9065a and ultrasound for approximately $24 \mathrm{~h}$. The change from baseline to follow-up of the right-to-left ventricular dimension ratio (RV/LV ratio) was obtained from reconstructed CT four-chamber views $[15,16]$. The change from baseline to follow-up of the CT-angiographic pulmonary clot burden was assessed by the modified Miller score [17].

\section{Data acquisition}

A 64 slice helical CT scanner was used for capturing CT images and $130 \mathrm{ml}$ of angiographic contrast material (Isovue 370) were infused at the rate of $5 \mathrm{ml}$ per second. The B40f convolution kernel was used to acquire and reconstruct ungated contrast-enhanced helical CT scans. The images were analysed at a window of width of 800-1000 after displaying on an off-line CT workstation (iCT; Philips Healthcare; Cleveland, $\mathrm{OH}$ ). The reconstructed four-chamber views, perpendicular to the interventricular septum and $1 \mathrm{~cm}$ apart from the atrioventricular annulus was 
used to obtain subannular right and left ventricular dimensions $[15,16]$. The pulmonary arteries were examined for the presence of clot (non-occlusive or occlusive). The modified Miller score (range 0 to 36 ) was calculated based on assigning 1 to non-occlusive emboli and the number of emboli in an occluded vessel was multiplied by two [17].

\section{Statistical analysis}

Discrete variables are reported as numbers with percentages and continuous data as mean and S.D. The change from baseline to follow-up of both the subannular RV/LV ratio and of the modified Miller score was assessed using oneway analysis of variance (ANOVA). Analyses were performed using Statistica (version 8.0). Differences were considered statistically significant at $p>0.005$.

\section{RESULTS}

The mean age of the patients was $69 \pm 13.5$ years (range, 28 - 77 years) and 35 were male (Table 1). Thirty six patients were at intermediate risk and 9 at high risk. Out of 45 patients 19 had at least one risk factor for bleeding complications, including age $>70$ years $(n=9)$, recent surgery $(n=5)$, cancer $(n=3)$ and severe renal dysfunction $(n=2)$. Baseline mean right ventricular end diastolic diameter was $53.5 \pm 8.4$ $\mathrm{mm}$ and baseline mean left ventricular end diastolic diameter was $37.5 \pm 6.3 \mathrm{~mm}$. Technical successes was achieved in all 45 patients. Thirty four patients $(75 \%)$ presented with bilateral PE and received two Ekosonic devices. Five patients (24\%) presented with unilateral PE and were treated with a single EkoSonic device. Overall, an initial bolus of $10.0 \pm 3.0 \mathrm{mg}$ DX-9065a was administered followed by a continuous infusion of $1.0 \pm 0.5 \mathrm{mg}$. Total mean DX-9065a dose was $45.0 \pm 10.0 \mathrm{mg}$ administered over a mean infusion duration of $20.5 \pm 5.6 \mathrm{~h}$ via the Ekosonic device. The Ekosonic device was removed promptly when the infusion was completed. The maximum allowed total DX-9065a dose was limited to $24 \mathrm{mg}$ and the maximum allowed infusion duration to $19 \mathrm{~h}$ (Table 2).
Table 1: Baseline characteristics of the patients enrolled for the study $(\mathrm{N}=45)$

\begin{tabular}{ll}
\hline Variable & $\mathbf{N}(\%)$ \\
\hline Age, mean (range) & $69 \pm 13.5(28-77)$ \\
Male (\%) & $35(77 \%)$ \\
Comorbidities (\%) & \\
Concomitant deep vein thrombosis & $32(71 \%)$ \\
Hypertension & $16(35 \%)$ \\
Hypercholesterolemia & $11(24 \%)$ \\
Recent major surgery & $5(11 \%)$ \\
Diabetes & $6(25 \%)$ \\
Cancer & $3(6 \%)$ \\
Tobacco use & $12(26 \%)$ \\
Hepatic or renal insufficiency & $2(4 \%)$ \\
Symptoms and hemodynamic & \\
status & $31(69 \%)$ \\
Dyspnea & $23(51 \%)$ \\
Hypoxemia & $14(31 \%)$ \\
Tachycardia & $7(15 \%)$ \\
Chest pain & $8(17 \%)$ \\
Hemoptysis & $4(8 \%)$ \\
Transient systemic hypotension & $6(13 \%)$ \\
Prolonged systemic hypotension & $4(8 \%)$ \\
Syncope & $6(13 \%)$ \\
Cough & $6(13 \%)$ \\
Cardiogenic shock & $2(4 \%)$ \\
Mechanical ventilation &
\end{tabular}

\section{End-point analysis}

Follow-up contrast enhanced CT studies were performed after $42 \pm 17 \mathrm{~h}$. No patients were receiving inotropic support at follow-up CT. The $\mathrm{RV} / \mathrm{LV}$ ratio decreased from $1.42 \pm 0.30$ to $1.00 \pm$ 0.02 at follow-up $(p<0.001)$. The mean right ventricular end diastolic diameter was reduced from $54.4 \pm 9.3 \mathrm{~mm}$ to $38.3 \pm 8.2 \mathrm{~mm}$ and the mean left ventricular end diastolic diameter increased from $42.3 \pm 7.2 \mathrm{~mm}$ to $38.2 \pm 8.6 \mathrm{~mm}$. The modified Miller score was significantly reduced from $23.2 \pm 4.7$ to $6.2 \pm 2.5(p>0.001)$ (Figure 2A, B).

\section{Clinical outcomes}

The average length of hospital stay for all the patients was $16 \pm 8$ days (range, 3 - 35 days) and in the intensive care unit was 3 days (median, 2 days). There were no systemic bleeding complications in the low-dose DX9065a patients. There were no systemic bleeding

Table 2: Dose regimens for recombinant tissue plasminogen activator administered via the EkoSonic devices

\begin{tabular}{lcc}
\hline Parameter & High dose group & Low dose group \\
& $(\mathbf{N}=\mathbf{3 2})$ & $\mathbf{( N )}=\mathbf{1 3})$ \\
\hline Total bolus, mean $\pm \mathrm{SD}, \mathrm{mg}$ & $8.4 \pm 3.2$ & $9.2 \pm 2.4$ \\
Bolus per device, mean $\pm \mathrm{SD}, \mathrm{mg}$ & $6.5 \pm 2.2$ & $5.0 \pm 1.0$ \\
Total infusion rate, mean $\pm \mathrm{SD}, \mathrm{mg}$ & $1.0 \pm 0.0$ & $0.3 \pm 0.1$ \\
Infusion duration, mean $\pm \mathrm{SD}$, hours & $23 \pm 7$ & $17 \pm 3$ \\
Total dose, mean $\pm \mathrm{SD}, \mathrm{mg}$ & $49.2 \pm 20.4$ & $21.6 \pm 4.5$ \\
\hline
\end{tabular}



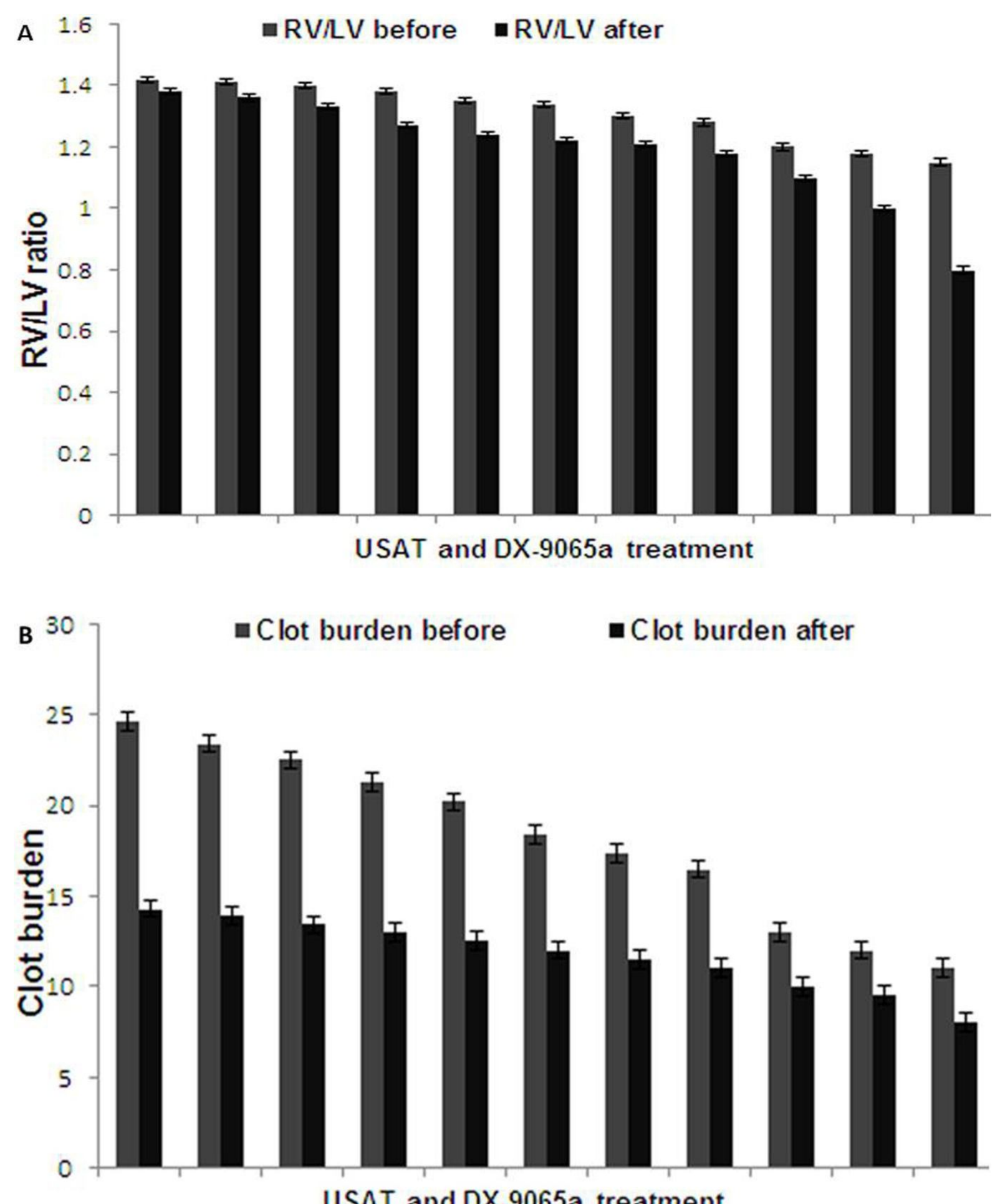

Figure 2: (A) RV/LV ratio and (B) modified miller index before and after USAT and DX-9065a. All measurements were within the limits of agreement (ie, within 2 SDs of the RV/LV ratio mean difference)

complications but 4 patients (8\%) from the highdose DX-9065a group suffered major access-site bleeding and required transfusion of packed red blood cells. Improvement in RV/LV ratio and modified miller score was similar in the low-dose and high-dose DX-9065a patients. There were no diagnosed recurrent clinical venous thromboembolic events during follow-up period of three months. 


\section{DISCUSSION}

The present study demonstrates the clinical effects of a pharmacomechanical catheter intervention using low-dose DX-9065a and ultrasound to rapidly improve right ventricular dysfunction in patients with acute PE. The use of thrombolysis in the management of high and intermediate risk PE is highly recommended [9]. Earlier reduction in the RV/LV ratio from 1.36 at baseline to 1.04 was achieved using weightadjusted intravenous tenecteplase over $24 \mathrm{~h}$ [10]. However the hemodynamic effects observed with full-dose intravenous thrombolysis could be achieved with USAT and low dose DX-9065a thrombolysis.

This study was designed to compare the effectiveness of USAT and DX-9065a for reversing right ventricular dilatation within $24 \mathrm{~h}$ in patients with high and intermediate risk PE. All the patients were discharged alive in our study and follow up was performed for 3 months. The RV/LV ratio was significantly reduced at the follow-up. The mean right ventricular end diastolic diameter was reduced whereas the mean left ventricular end diastolic diameter was increased. The modified Miller score was significantly reduced from $23.2 \pm 4.7$ to $6.2 \pm 2.5$. Complications of pulmonary catheter interventions have not been reported with the Ekosonic System but may include perforation or dissection of cardiovascular structures, pericardial tamponade, pulmonary hemorrhage, and distal thrombus embolization [18].

There are reports that dissolution of vascular blood clots can be achieved rapidly using ultrasound and urokinase or rt-PA but not by ultrasound alone [19-23]. It is reported that disaggregation of fibrin stands and increase in clot permeability occurs by ultrasound [25]. The infused DX-9065a is forced and bound with exposed plasminogen receptor sites. The bound DX-9065a is then protected from deactivation by anti-plasmin proteins. In patients with stroke [24], peripheral arterial occlusion [25], DVT [26] and PE $[27,28]$ the EKOS system has been used. USAT treatment was used in 10 acute PE patients [27]. Our study was designed to investigate the contribution of DX-9065a, ultrasound and anticoagulation therapy on the recovery of right ventricular dilatation and clot burden.

\section{CONCLUSION}

USAT and DX9065a in low-dose are an efficient strategy for reversal of right ventricular dilatation and reduction of pulmonary clot in patients with intermediate- and high-risk PE.

\section{REFERENCES}

1. Alikhan $R$, Peters $F$, Wilmott $R$, Cohen AT. Fatal pulmonary embolism in hospitalized patients: a necropsy review. J Clin Pathol 2004; 57: 1254-1257.

2. Anderson FA Jr, Spencer FA. Risk factors for venous thromboembolism. Circulation 2003; 107: 19-16.

3. Wood K. Major pulmonary embolism: review of pathophysiology approach to the golden hour of hemodynamically significant pulmonary embolism. Chest 2002; 121: 877-905.

4. Ryu JH, Olson EJ, Pellikka PA. Clinical recognition of pulmonary embolism: problem of unrecognized and asymptomatic cases. Mayo Clin Proc 1998; 73: 873879.

5. Dalen JE, Alper JS. Natural history of pulmonary embolism. Prog Cardiovasc Dis 1975; 17: 259-270.

6. Murin S, Romano PS, White RH. Comparison of outcomes after hospitalization for deep venous thrombosis or pulmonary embolism. ThrombHaemost 2002; 88: 407-414.

7. Van Beek EJ, Brouwerst EM, Song B, Stein PD, Oudkerk M. Clinical validity of a normal pulmonary angiogram in patients with suspected pulmonary embolism a critical review. ClinRadiol 2001; 56: 838-842.

8. Goldhaber SZ, Visani L, De Rosa M. Acute pulmonary embolism: clinical outcomes in the International Cooperative Pulmonary Embolism Registry (ICOPER). Lancet 1999; 353: 1386-1389.

9. Kearon C, Kahn S, Agnelli G, Goldhaber G, Raskob GE, Comerota AJ. Antithrombotic therapy for venous thromboembolic disease: American College of Chest Physicians evidence based clinical practice guidelines. Chest, 8th edition, 133 (6 Suppl); 2008. pp 454S-545S.

10. Becattini C, Agnelli G, Salvi A. Bolus tenecteplase for right ventricle dysfunction in hemodynamically stable patients with pulmonary embolism. Thromb Res 2010; 125: e82-6.

11. Konstantinides S, Tiede N, Geibel A, Olschewski M, Just $H$, Kasper W. Comparison of alteplase versus heparin for resolution of major pulmonary embolism. Am J Cardiol 1998; 82: 966-970.

12. Goldhaber SZ. Pulmonary embolism. N Engl J Med 1998; 339: 93-104.

13. Tod C, Engelhardt AJ, Taylor LA, Simprini NK. Catheterdirected ultrasound-accelerated thrombolysis for the treatment of acute pulmonary embolism. Thrombosis Research 2011; 128: 149-154.

14. Tamaru Y, Kawamura S, Bando T, Tanaka IC, Hojo M, Yoshida Z. J. Org. Chem. 1988; 53: 5491-5493.

15. Quiroz R, Kucher N, Schoepf UJ. Right ventricular enlargement on chest computed tomography: prognostic role in acute pulmonary embolism. Circulation 2004; 109: 2401-2404.

Trop J Pharm Res, August 2015; 14(8): 1479 
16. Schoepf UJ, Kucher N, Kipfmueller F, Quiroz R, Costello $P$, Goldhaber SZ. Right ventricular enlargement on chest computed tomography: a predictor of early death in acute pulmonary embolism. Circulation 2004; 110: 3276-3280.

17. Araoz PA, Gotway MB, Harrington JR, Harmsen WS, Mandrekar JN. Pulmonary embolism: prognostic CT findings. Radiology 2007; 242: 889-897.

18. Kucker N, Goldhaber SZ. Management of massive pulmonary embolism. Circulation 2005; 112: e28-32.

19. Braaten JV, Goss RA, Francis CW. Ultrasound reversibly disaggregates fibrin fibers. Thromb Haemost 1997; 78: 1063-1068.

20. Francis $C$, Blinc A, Lee S, Cox C. Ultrasound accelerates transport of recombinant of recombinant tissue plasminogen activator into clots. Ultrasound Med Biol 1995; 21: 419-424.

21. Siddiqi F, Odrljin TM, Fay PJ, Cox C, Francis CW. Binding of tissue-plasminogen activator to fibrin: Effect of ultrasound. Blood 1997; 91: 2019-2025.

22. Lauer CG, Burge R, Tang DB, Bass BG, Gomez ER, Alving $B M$. Effect of ultrasound on tissue-type plasminogen activator-induced thrombolysis. Circulation 1992; 86: 1257-1264.
23. Harpaz D, Chen X, Francis CW, Marder VJ, Meltzer RS. Ultrasound enhancement of thrombolysis and reperfusion in vitro. J Am Coll Cardiol 1993; 21: 15071511.

24. IMS II Trial Investigators. Interventional Management of Stroke (IMS) II Study. Stroke 2007; 38: 2127-2135.

25. Wissgott C, Richter A, Kamsuella P, Steinkamp HJ. Treatment of critical limb ischemia using ultrasound enhanced thrombolysis (PARES-Trial): final results. $J$ Endovasc Ther 2007; 14: 438-443.

26. Parikh S, Motarjeme A, McNamara T, et al. Ultrasound accelerated thrombolysis for the treatment of deep vein thrombosis: initial clinical experience. J Vasc Interv Radiol 2008; 19: 5213-5216.

27. Chamsuddin A, Nazzal L, Kang B, et al. Catheterdirected Thrombolysis with the Endowave System in the Treatment of Acute Massive Pulmonary Embolism: A Retrospective Multicenter Case Series. J Vasc Interv Radiol 2008; 19: 372-376.

28. Lin PH, Annambhotla S, Bechara CF, et al. Comparison of percutaneous ultrasound accelerated thrombolysis versus catheter-directed thrombolysis in patients with acute massive pulmonary embolism. Vascular 2009; 17: S137-S147. 